\title{
Исследования сорбционных свойств обратноосмоти- ческой эфирсульфонполиамидной мембраны мето- дами рентгенодифрактометрии и дифференциальной сканирующей калориметрии
}

\author{
Лазарев С.И. ${ }^{1}$, Головин Ю.М. ${ }^{1}$, Яновская Э.Ю. ${ }^{2}$, Ковалева О.А. ${ }^{1}$, \\ Лазарев Д.С. ${ }^{1}$, Вязовов С.А ${ }^{1}$. \\ ${ }^{1}$ ФГБОУ ВО «Тамбовский государственный технический университет», Тамбов \\ ${ }^{2}$ ФГБОУ ВПО «Российский научно-исследовательский медииинский университет им. Н.И. Пирогова», \\ Москва
}

Поступила в редакцию 29.06.2016 г.

\begin{abstract}
Проведены исследования структурных свойств композиционной обратноосмотической эфирсульфонполиамидной мембраны ESPA1 методами рентгенодифрактометрии и дифференциальной сканирующей калориметрии (ДСК). Установлено, что в процессе водо-набухания эфирсульфонполиамидной мембраны наблюдается уменьшение рентгеновской степени кристалличности (СК). Дифференциальная сканирующая калориметрия ДСК надежно фиксирует эндотермический пик бимодальной формы при температурах 250 и $254^{\circ} C$, отвечающих за плавление кристаллических фаз. Снижение степени кристалличности при сорбции воды, скорее всего, связано с перераспределением соотношения между количеством совершенных по структуре кристаллических фаз в кристаллитах полиамида 6.6 , имеющих разные величины энтальпии плавления.
\end{abstract}

Ключевые слова: сорбционные свойства, кристалличность, аморфность, эфирсульфонполиамидная мембрана, эндотермический эффект.

\section{Research of sorption properties efirsulfonpoliamidnoy membrane techniques X-ray diffraction and differential scanning calorimetry}

\author{
Lazarev S.I. ${ }^{1}$, Golovin Yu.M. ${ }^{1}$, Yanovskaya E.Yu. ${ }^{2}$, Kovaleva O.A. ${ }^{1}$, \\ Lazarev D.S. ${ }^{1}$, Viazovov S.A. ${ }^{1}$ \\ Tambov State Technical University, Tambov \\ NATIONAL HPE "Russian scientific research medical University n. a. N. And. Pirogov", Moscow
}

Investigations of the structural properties of the composite reverse osmosis membrane efirsulfonpoliamidnoy the ESPA methods of X-ray diffraction and differential scanning calorimetry (DSC). It was found that in the process vodonabuhanie efirsulfonpoliamidnoy membrane, a decrease of X-ray degree of crystallinity (IC). Differential scanning calorimetry DSC endotherm reliably fixes bimodal shape at temperatures of $250^{\circ} \mathrm{C}$ and $254^{\circ} \mathrm{C}$ responsible for melting the crystalline phase. Reduction in the degree of crystallinity of water sorption is likely due to the redistribution between the amount ratio and better less crystalline phases in the polyamide 6.6 crystallites having different values of the melting enthalpy.

Keywords: sorption processes, crystallinity, amorphousness, efirsulfonpoliamidnaya membrane endothermic effect. 


\section{Введение}

Исследования структуры и процессов, происходящих в полимерных мембранах при их эксплуатации физическими методами, являются актуальной задачей и в настоящее время [1-3]. Методами рентгено-электронной (РЭМ) и атомно-силовой микроскопии (АСМ) проведены исследования влияния структуры и морфологии поверхности, однородных по толщине ионообменных мембран на процессы, происходящие в электродиализных методах [1-2]. В работе [3] изучены влияния электрической неоднородности поверхности гетерогенных ионообменных мембран на электрохимические характеристики. Сравнения вольтамперных (BAX) кривых мембран выявили уменьшение предельной диффузионной плотности тока, удлинение и рост сопротивления участка плато предельного тока ВАХ для мембран производства ООО «Щекиноазот». Однако, в литературных источниках отсутствуют исследования структуры и влияния её на сорбционные явления, происходящие в полупроницаемых мембранах, представляющие собой многослойную композицию (ассиметричные мембраны) и состоящие из различных по химическому строению полимеров (аморфности и кристалличности). Согласно одной из гипотез по переносу веществ в полупроницаемых мембранах, она состоит из кристаллической фазы и аморфных областей, через которые переносятся вещества конвекцией и диффузией [4], что является весьма востребованной и интересной задачей в научном и практическом планах. В данной работе выполнены исследования надмолекулярных образований и их структурных превращений в эфирсульфонполиамидной мембране ESPA1 при сорбции воды методами рентгенодифрактометрии и дифференциально-сканирующей калориметрии.

\section{Эксперимент}

Рентгенодифракционные исследования образцов мембраны ESPA1 были выполнены на дифрактометре Дрон-3 в автоматизированном режиме, поддерживаемом программным пакетом Lgraf-2 и Difwin, в области больших углов $2 \theta$ от $5^{0}-35^{0}$. Запись рентгенограмм производилась от воздушносухого и водонасыщаемого в течение 24 часов образцов в геометрии на отражение с шагом $0.01^{0}$. Использовалось излучение $\mathrm{CuK}_{\alpha}(\lambda=1.54 \stackrel{0}{A})$. Монохроматизация обеспечивалась Ni-фильтром. Ток и напряжение на рентгеновской трубке имели значение 20 мА и 35 кВ.

Полученные экспериментальные данные из пакета Difwin-1 для дальнейшей интерпретации и идентификации фазового состава мембраны передавались в программный пакет Origin 7.5 на ПК. Теплофизические характеристики образцов мембраны ESPA1 измерялись на дифференциальном сканирующем калориметре ДСК- 2 со скоростью нагрева $10^{\circ} \mathrm{C}$ в минуту и интервале температур от 50 до $300^{\circ} \mathrm{C}$.

\section{Обсуждение результатов}

Ранее проведенные исследования по рентгенодифрактометрии в области малых и больших углов рассеивания, инфрокрасноскопии, термогравомитрии и диффренциально-сканирующей калометрии исследования мембраны МГА-95 показали, что она представляют собой сложную суперпозицию нескольких слоев и имеет меняющиеся, по структуре аморфные, кристаллические и поровые области [5-7]. Кривые интенсивности рентгеновского рассеяния обоих образцов мембраны ESPA1 практически идентичны, на них наблюдаются три ярко выраженные дифракционные 
рефлексы при углах $2 \theta=17.75^{0}, 22.84^{0}, 25.97^{0}$, на фоне аморфного гало $2 \theta$ от $7^{0}$ до $35^{0}$ (рис.1).

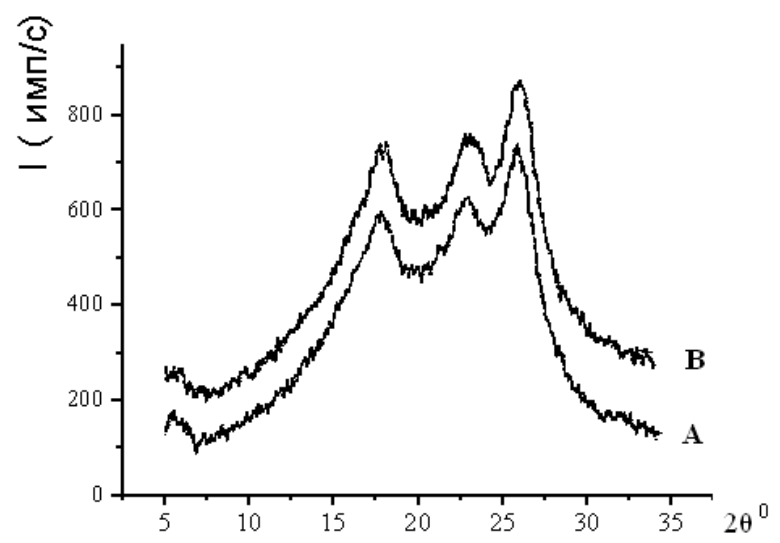

Рис.1. Экспериментальные рентгеновские дифрактограммы эфирсульфонполиамидной мембраны ESPA-1, полученные в геометрии на отражение:

А - воздушно-сухой образец; В - водо-насыщенный образец.

Дифракционные кривые, приведенные на рис. 1, несмотря на общую схожесть, имеют ряд характерных отличий. Заметно смещение кривой интенсивности для водо-насыщенного образца в больше угловую область рассеяния. Также обнаруживается незначительное перераспределение интенсивностей рассеяния при углах дифракции $17^{0}, 83^{0}$ и $25.97^{0}$. Поэтому, для количественного описания наблюдаемых изменений в эфирсульфонполиамидной мембране ESPA1, которые связаны не только в силу многослойности композиции, но и многообразия возможных конформаций макромолекул полиэфирсульфона и полиамида, был проведен полно-профильный анализ кривых интенсивности рентгеновского рассеяния для воздушно-сухого и водо-насыщенного образцов. Для этого из первичных рентгенограмм предварительно вычитался традиционным методом фон некогерентного рассеяния, проводя касательную к точкам кривой интенсивности рентгеновского рассеяния при углах $2 \theta$ от $7^{0}$ до $35^{0}$. Особенности рентгеновского спектра в указанном интервале углов дифракции были смоделированы пятью гауссианами. Рассчитанная недостоверность для варианта полно-профильного анализа кривых интенсивности рентгеновского рассеяния для образцов составила: 5\%-воздушно-сухого и 5.2\%-водо-насыщенного. Профили широко-углового рассеяния представлены на рис. 2а и 26.

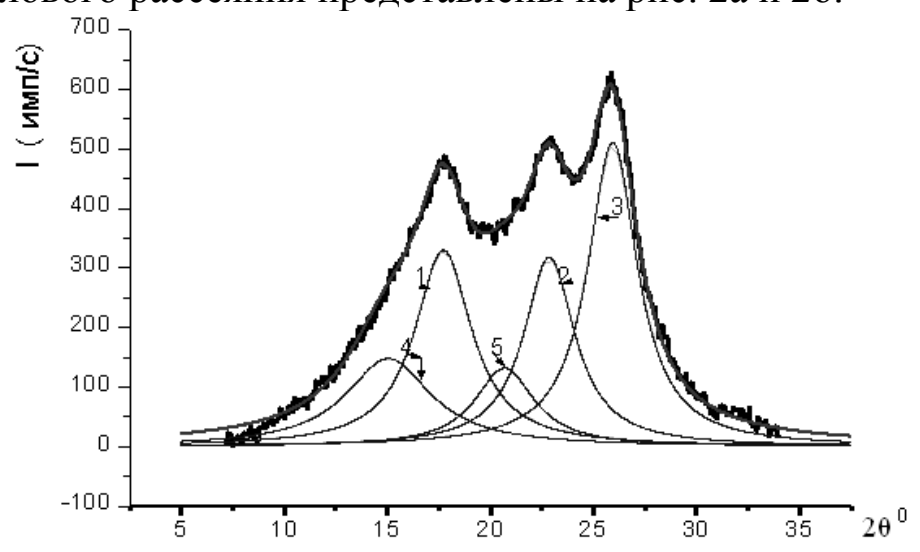

Рис. 2а. Результаты профильного анализа экспериментальной дифрактограммы на отражение для воздушно-сухого образца мембраны ESPA1: 1, 2, 3 - гауссианы кристаллической фазы полиамида; 4 - гауссиан аморфной фазы полиамида; 5 - гауссиан аморфного эфирсульфона. 


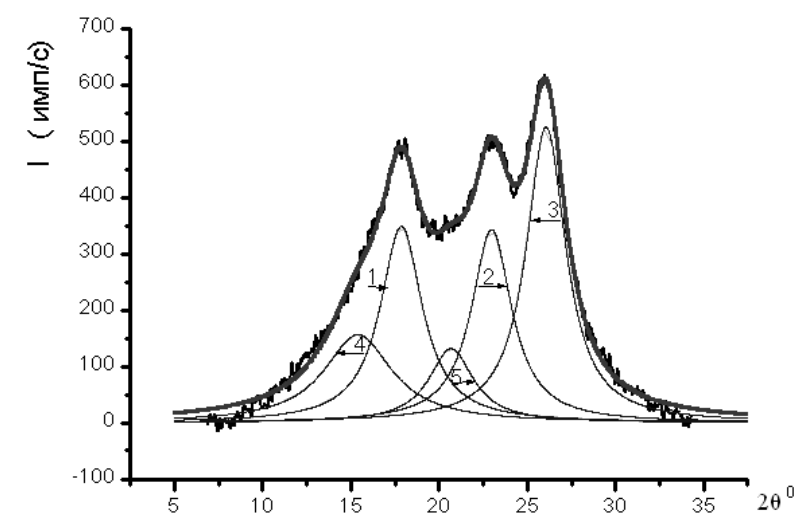

Рис. 2б. Результаты профильного анализа экспериментальной дифрактограммы на отражение для водо-насыщенного образца мембраны ESPA1: 1, 2, 3 - гауссианы кристаллической фазы полиамида; 4 - гауссиан аморфной фазы полиамида;

5 - гауссиан аморфного эфирсульфона.

Размер кристаллитов области когерентного рассеяния (ОКР) определяли по соотношению Селякова-Шеррера

$$
L_{\kappa p}=\lambda \cdot\left(\beta \cos \frac{2 \theta}{2}\right)^{-1},
$$

Характерные расстояния в структуре вычисляли методом Вульфа-Брэггов,

$$
d=\lambda \cdot(2 \sin \vartheta)^{-1} \text {. }
$$

где $\lambda=1.542 \stackrel{0}{A}, \beta$ - полуширина пика в радианах, $\theta$ - угол дифракции.

Рассчитанные параметры надмолекулярной структуры при полнопрофильном анализе для воздушно-сухого и водо-насыщенного образцов приведены в табл. 1 и 2.

Таблица 1. Рассчитанные параметры надмолекулярной структуры при полно-

\begin{tabular}{|c|c|c|c|c|c|}
\hline $\begin{array}{c}\text { Угол } \\
\text { Параметры } \\
\end{array}$ & $2 \theta_{1}$ & $2 \theta_{2}$ & $2 \theta_{3}$ & $2 \theta_{4}$ & $2 \theta_{5}$ \\
\hline Эксперимент & - & 17.75 & - & 22.84 & 25.97 \\
\hline При моделировании & 15.05 & 17.72 & 20.69 & 22.84 & 25.93 \\
\hline $\begin{array}{c}0 \\
\mathrm{~d}(A) \text { максимальное расстояние }\end{array}$ & 5.90 & 5.01 & 4.29 & 3.89 & 3.44 \\
\hline $\begin{array}{r}0 \\
\text { Размеры ОКР L }(A)\end{array}$ & 16.6 & 24.98 & 27.34 & 27.49 & 31.77 \\
\hline $\begin{array}{c}\text { Относительная интегральная ин- } \\
\text { тенсивность, С, \% }\end{array}$ & 14.5 & 25.5 & 9.7 & 21.5 & 29.5 \\
\hline $\begin{array}{c}\beta \text { (полуширина рефлекса, } \\
\text { градусы) }\end{array}$ & 53 & 3.37 & 3.51 & 3.09 & 2.68 \\
\hline Степень кристалличности, \% & & & 75.8 & & \\
\hline
\end{tabular}
профильном анализе для воздушно-сухого образца

Анализ профилей интенсивности широко-углового рассеяния (табл. 1 и 2) и данных работ других авторов [8-11] дает неожиданные результаты. Прежде всего, коммерческая эфирсульфонполиамидная мембрана ESPA1 представляет собой не трехслойную, а двухслойную композицию из основного полиамидного и очень тонкого полиэфирсульфонного слоев. Согласно литературным данным [8-9], полиамид при различных технологических процессах кристаллизуется в двух модификациях 
$\alpha$ и $\gamma$ фазах и образует моноклинную элементарную ячейку с характерными пиками на дифрактограмме $2 \theta=20.5^{0}, 24.3^{0}$ ( $\alpha$ фаза) и $2 \theta=21.5^{0}$ ( $\gamma$ фаза). В работе [9] дифракционные рефлексы, приведенные на рентгенограммах, соответствуют $2 \theta=18.5^{0}, 25.5^{0}$ и $22.5^{0}$. Полиэфирсульфон является аморфным полимером и на рентгенограмме фиксируется широким диффузным гало с центром тяжести при угле $2 \theta=19^{0}[11-13]$.

Таблица 2. Рассчитанные параметры надмолекулярной структуры при полнопрофильном анализе для водо-насыщенного образца

\begin{tabular}{|c|c|c|c|c|c|}
\hline $\begin{array}{c}\text { Угол } \\
\text { Параметры } \\
\end{array}$ & $2 \theta_{1}$ & $2 \theta_{2}$ & $2 \theta_{3}$ & $2 \theta_{4}$ & $2 \theta_{5}$ \\
\hline Эксперимент & - & 17.83 & - & 23.07 & 26.11 \\
\hline При моделировании & 15.40 & 17.86 & 20.65 & 22.97 & 26.06 \\
\hline $\mathrm{d}(\stackrel{0}{A})$ максимальное расстояние & 5.80 & 4.97 & 4.30 & 3.89 & 3.43 \\
\hline $\begin{array}{c}0 \\
\text { Размеры ОКР }(A) \\
\end{array}$ & 19.1 & 29.57 & 28.4 & 30.83 & 31.39 \\
\hline $\begin{array}{c}\text { Относительная интегральная ин- } \\
\text { тенсивность, С, \% }\end{array}$ & 16.24 & 22.3 & 8.8 & 21.1 & 31.56 \\
\hline$\beta$ (полуширина рефлекса, гра- & 4.4 & 2.9 & 2.97 & 2.77 & 2.72 \\
\hline Степень кристалличности, \% & & & 74.90 & & \\
\hline
\end{tabular}

Несмотря на тщательность и точность проведения исследований, отметим, что полученные нами экспериментальные результаты имеют небольшой разброс, приблизительно на $1.5^{0}$. Также отсутствие сведений о химическом строении макромолекул полиамида ПА-6 или ПА-6.6 в коммерческой мембране ESPA1 не позволяет зарегистрированные дифракционные рефлексы однозначно отнести к той или иной фазе полиамида. Однако, характер и распределение их на общей кривой интенсивности рассеяния не вызывает сомнения о двухфазной структуре полиамида. Смещение угловых значений в пределах возможных экспериментальных погрешностей дифракционных рефлексов в больше угловую область дифракций свидетельствует о компактности структуры макромолекул в полиамидном слое. Из приведенных расчетов структурных параметров образцов мембраны ESPA1 видно (табл. 1 и 2), что надмолекулярные изменения происходят как в аморфных, так и кристаллических областях полиамида, но незначительны в полиэфирсульфонном слое [5-7]. Так, максимальный угол дифракции от аморфной фазы полиамида смещается от $15.05^{0}$ воздушно-сухого до $15.40^{0}$ водо-насыщенного образцов соответственно. Одновременно увеличиваются размеры аморфной фазы на $15 \%$ и растет интенсивность рефлекса. Это дает основание предположить, что при сорбции молекул воды меняется упаковка макромолекул полиамида, увеличивая плотность аморфной фазы. Что касается кристаллической фазы, то при водонасыщении образца мембраны заметно изменяются размеры кристаллитов ОКР в перпендикулярном направлении к кристаллографической плоскости, определяемой рефлексом при угле $2 \theta=22.84^{0}$ от $27.49 \stackrel{0}{A}$ до $30.83 \stackrel{0}{A}$, без изменения межплоскостных расстояний между макромолекулами и интенсивности рефлекса. Это, очевидно, указывает на формирование более совершенной степени упорядочения макромолекул (в кристаллографическом смысле), но не на количественную долю кристаллитов. Размеры ОКР рассчитанные для угла рефлекса $2 \theta=17.75^{\circ}$ увеличиваются от 24.98 до $29.57 \stackrel{0}{A}$ с уменьшением относительной 
интегральной интенсивности рентгеновского рассеяния с 25.5 до 22.3\%. Для угла $2 \theta=25.97^{0}$ размеры ОКР уменьшаются с 31.77 до $31.39 \stackrel{0}{A}$, при увеличении интенсивности с 29.5 до $31.56 \%$. Если предположить, что эти рефлексы относятся к различным кристаллографическим плоскостям элементарной ячейки одной фазы, то данный эффект, скорее всего, является следствием конформационных изменений макромолекул полиамида в кристаллите [8]. Характер этих изменений определяет уменьшение полуширины рефлексов водо-насыщенного образца [5-6].

Поскольку из анализа дифрактограмм известен вклад каждого рефлекса в общую кривую распределения интенсивности рассеяния от различных кристаллографических плоскостей кристаллической и макромолекул аморфной фаз, то можно определить их соотношение в полимерной мембране по формуле:

$$
C_{2}=\frac{I_{i}(2 \theta)}{\sum_{1}^{5} I_{i}(2 \theta)},
$$

где $I_{i}(2 \theta)$ - интегральная интенсивность $i$-рефлекса, $\sum_{1}^{5} I_{i}(2 \theta)$ - интегральная интенсивность суммарной кривой по всей области моделирования $2 \theta$ от $7^{0}$ до $35^{0}$.

Разделение кривой интенсивности рассеяния на пять гауссианов с выделением аморфных и кристаллических областей, позволяет оценить общую степень рентгеновской кристалличности мембраны методом суммирования относительных интегральных интенсивностей рентгеновских пиков, отнесенных к кристаллической фазе. Рентгеновская степень кристалличности мембраны ESPA1 воздушно-сухого образца оказалась равной $75.8 \%$, а для водо-насыщенного - 74.96\%, это коррелируется с низким процентом сорбирования воды в мембране [14].

Таким образом, основные структурные изменения при процессе набухания происходят в аморфной и кристаллической фазах полиамида. Смещение аморфного гало в область больших углов рассеяния указывает на увеличение плотности упаковки макромолекул. Незначительные изменения степени кристалличности, скорее всего, связаны с перераспределением состава кристаллических фаз в кристаллитах полиамида. Аморфный полиэфирсульфонный слой практически не влияет на общую структуру мембраны ESPA1 (табл. 1 и 2). Эволюцию микроструктуры образцов мембраны в дополнение к рентгеновскому анализу исследовали методом дифференциальной сканирующей калориметрии. Экспериментальные кривые ДСК представлены на рис. 3.

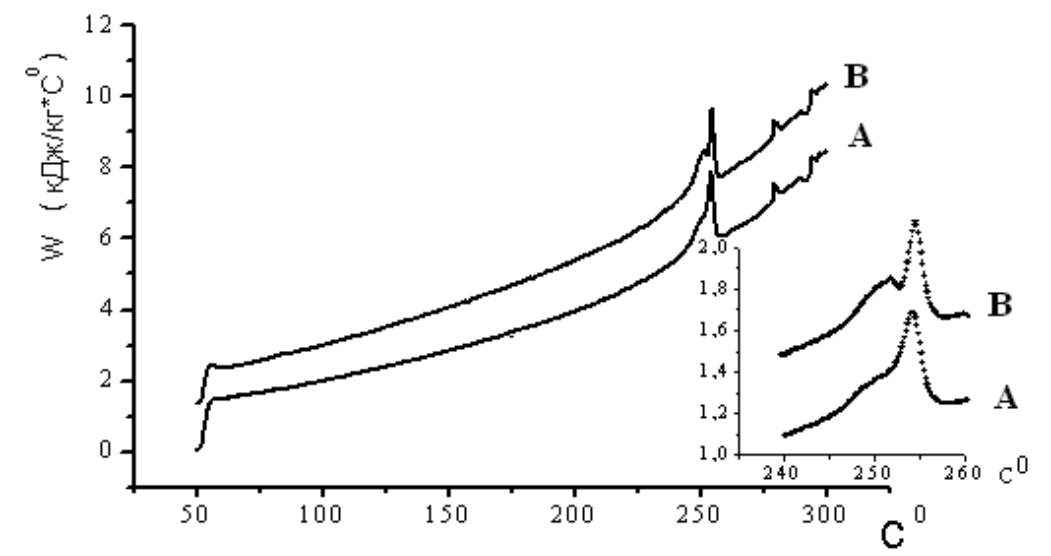

Рис. 3. Экспериментальные кривые ДСК образцов мембраны ESPA1: A - водонасыщенный: В - воздушно-сухой. 
На кривых ДСК проявляется сложный пик эндотермического эффекта бимодальной формы в области температур $250-254^{0}$ C. Характерной особенностью пика является медленный рост со стороны низких температур и резкий спад в области высоких температур (показано на вставке рис. 3), что отражает протекание фазовых превращений, накладываемых друг на друга.

Для выявления возможных фазовых превращений был проведен полнопрофильный анализ данных эндотермических пиков на кривых ДСК (рис. 4 а и 4 б), результирующая кривая двух гауссианов.

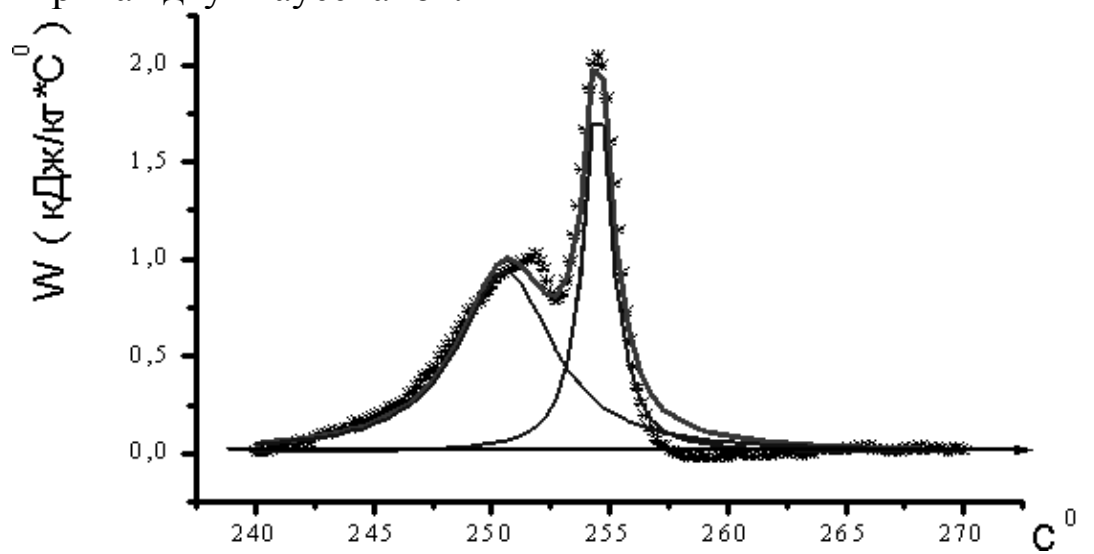

Рис. 4а. Полно-профильный анализ воздушно-сухого образца мембраны ESPA-1: *- эксперимент - - результат аппроксимации.

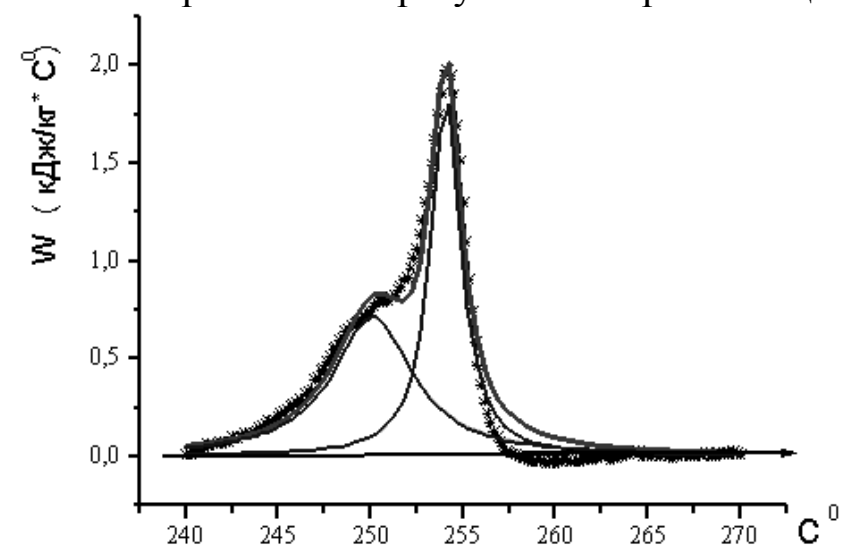

Рис. 4б. Полно-профильный анализ водо-насыщенного образца мембраны ESPA1: *- эксперимент; - - результат аппроксимации.

Наиболее удовлетворительное совпадение экспериментальных и теоретических кривых было получено суперпозицией двух гауссианов с индексом недостоверности менее $12 \%$ (табл. 3).

Как следует из расчетов, на кривых ДСК присутствует эндотермический узкий пик при температуре $254.07^{\circ} \mathrm{C}, 254.49^{\circ} \mathrm{C}$, а также широкий менее интенсивный пик при температуре $250.6^{\circ} \mathrm{C}$ и $250.11^{\circ} \mathrm{C}$ для воздушно-сухого и водо-насыщенного образцов. Это свидетельствует о гетерогенности кристаллической фазы полиамида, состоящей из низкотемпературной $-250^{\circ} \mathrm{C}$ и высокотемпературной $-254^{\circ} \mathrm{C}$ составляющих фаз. Отметим, что температура плавления кристаллического полиамида 6.6 равна $254^{\circ} \mathrm{C}$. Поскольку гетерогенная система представляет собой аддитивную сумму вкладов каждой фазы, то площади пиков характеризуют содержание кристаллических фаз в образцах. По рассчитанным площадям пиков было определено относительное содержание кристаллических фаз в образцах и их изменение при сорбции воды (табл. 3). Величина эндотермических пиков указывает на незначительное снижение кристалличности в водо-насыщенном образце мембраны, так удельная тепло- 
та плавления (энтальпия) изменяется с 12.18 кДж/кг до 11.66 кДж/кг, что согласуется с рентгеновской степенью кристалличности с 75.8 до $74.96 \%$.

Таблица 3. Теплофизические характеристики образцов мембраны ESPA1, рассчитанные по данным ДСК

\begin{tabular}{|c|c|c|c|}
\hline № $\Pi / \Pi$ & $\begin{array}{c}\text { Физические } \\
\text { величины }\end{array}$ & Воздушно-сухой образец & Водо-насыщенный образец \\
\hline 1 & $\mathrm{~T}_{\text {пл. } 1},{ }^{0} \mathrm{C}$ & 250.6 & 250.11 \\
\hline 2 & $\mathrm{~S}_{\text {пл. } 1, \mathrm{\kappa Дж/кГ}}$ & 7.83 & 5.93 \\
\hline 3 & 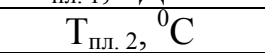 & 254.49 & 254.07 \\
\hline 4 & $\mathrm{~S}_{\text {пл. 2, кДж/кг }}$ & 4.35 & 5.73 \\
\hline 5 & $\sum_{1}^{2} S_{i}$, кДж/кг & 12.18 & 11.66 \\
\hline 6 & $C_{1}={\frac{S_{1}}{\sum_{1}^{2} S_{i}}}^{\%}$ & 64.3 & 50.9 \\
\hline 7 & 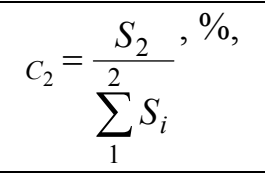 & 35.72 & 49.1 \\
\hline
\end{tabular}

\section{Заключение}

Проведенные экспериментальные и теоретические исследования методами рентгенодифрактометрии и дифференциальной сканирующей калориметрии доказывают что, во-первых, коммерческая мембрана ESPA1 состоит из тонкого активного аморфного полиэфирсульфонного и в основном кристаллического дренажного полиамидного слоя П6.6, во-вторых, основные структурные изменения при процессе водо-набухания происходят как в аморфной, так и кристаллической фазах полиамида, наблюдаемое смещение аморфного гало в область больших углов рассеяния свидетельствует о повышении плотности упаковки макромолекул в аморфной фазе, втретьих, надмолекулярная структура аморфного полиэфирсульфонного слоя практически не изменяется при сорбции воды. Снижение степени кристалличности при сорбции воды, скорее всего, связано с перераспределением соотношения между количеством совершенных кристаллических фаз в кристаллитах полиамида, имеющих разные величины энтальпии плавления, для низкотемпературной фазы наблюдается уменьшение - с 7.83 до 5.93 кДж/кг, а высокотемпературной - увеличение- с 4.35кДж/кг до 5.73 кДж/кг при водонасыщении.

\section{Список литературы}

1.Васильева В.И., Кранина М.Д., Малыхин Э.М. и др. // Поверхность. Рентгеновские, синхротронные и нейтронные исследования. 2013. № 2. C. 51-61.

2. Васильева В.И., Акберова Э. М., Жильцова А.В. и др. // Поверхность. Рентгеновские, синхротронные и нейтронные исследования. 2013. № 9. С. 27-34.
3. Васильева В.И., Жильцова А.В., Акберова Э. М. // Конденсированные среды и межфазныле границьы. 2014. Т. 16. № 3. С. 257261.

4. Ивара М. // Перевод с японского языка из журнала «Хёмэи». 1978. Т.16. № 7. С.399412. Перевод №Г-16892 ВЦП. М. 1981. 38 с. 
5. Lazare S.I., Golovin Yu.M., Kovalev S.V.// Theoretical Foundations of Chemical Engineering. 2016. Vol. 50. No 3. pp. 294-302.

6. Лазарев С.И., Головин Ю.М., Шестаков К.В., Яновская Э.Ю. и др. // Сорбиионные и хроматографические проиессы. 2016. № 3. C.333-340.

7. Lazarev S.I., Golovin Yu.M., Lazarev D.S., Polikarpov V.M. // Petroleum Chemistry. 2015. Vol. 55. No 10. pp. 791-794.

8. Новаков И.А., Рахимова Н.А. // Известия ВолгГТУ. 2009. Т. 2. № 6. С. 5-29.

9. Avlar S., Qiao Yu // Composites. Part A. 2005. Vol. .36. p. 624.

\section{References}

1.Vasil'eva V.I., Kranina M.D., Malykhin E.M. et al., Poverkhnost'. Rentgenovskie, sinkhrotronnye $i$ neytronnye issledovaniya. 2013, No 2, pp. 51-61.

2. Vasil'eva V.I., Akberova E.M., Zhil'tsova A.V. et al., Poverkhnost'. Rentgenovskie, sinkhrotronnye $i$ neytronnye issledovaniya, 2013, No 9, pp. 27-34.

3. Vasil'eva V.I., Zhil'tsova A.V., Akberova E.M. Kondensirovannye sredy $i$ mezhfaznye granitsy, 2014, Vol. 16, No 3,. pp. 257- 261.

4. Ivara M., Perevod s yaponskogo yazyka iz zhurnala "Hyomehi", 1978. T.16, №7.S.399412. Perevod №G-16892 VCP. M. 1981. $38 \mathrm{~s}$.

5. Lazare S.I., Golovin Yu.M., Kovalev S.V., Theoretical Foundations of Chemical Engineering, 2016, Vol. 50, No 3, pp. 294-302.

6. Lazarev S.I., Golovin YU.M., SHestakov K.V., YAnovskaya E.Yu. et al, Sorbtsionnye $i$ khromatograficheskie protsessy, 2016, No 3, pp. 333-340.

Лазарев Сергей Иванович - зав. кафедрой, д.т.н., профессор, каф. Прикладная геометрия и компьютерная графика, ТГТУ, Тамбов

Головин Юрий Михайлович - доцент, к.х.н., доцент, каф. Физика, ТГТУ, Тамбов

Яновская Эллина Юрьевна - доцент, к.м.н., каф. педиатрии, ГБОУ ВПО РНИМУ, Москва

Лазарев Дмитрий Сергеевич - студент, ТГТУ, Тамбов

Вязовов Сергей Александрович - доцент, к.т.н., ТГТУ, Тамбов

Ковалева Ольга Александровна - доцент, к.т.н., каф. ПГ и КГ ТГТУ, Тамбов
10, Надольский А.Л. Рентгенография полимеров. Екатеринбург. Уральский федеральный университет. 2013. 45 с.

11. Батырина Р.Т. Автореф. дис. к-та техн. наук. Казань. КГТУ. 2013. 16 с.

12. Лепешин С.А. Автореф. дис. к-та техн. наук. Казань. КНИТУ. 2016. 18 с.

13. Цванкина А.Л. Автореф. дис. к-та хим .наук. М. 1985.16 c.

14. Карсакова Е.В, Кравченко Т.П. // Усneхи в химии и химической технологии. 2008. T.22. №5 (85). C. 10-13.

7. Lazarev S.I., Golovin Yu.M., Lazarev D.S., Polikarpov V.M., Petroleum Chemistry, 2015, Vol. 55, No 10, pp. 791-794.

8. Novakov I.A., Rakhimova N.A. Izvestiya VolgGTU, 2009, Vol. 2, No 6, pp. 5-29.

9. Avlar S., Qiao Yu., Composites. Part A, 2005, Vol, 36, $624 \mathrm{p}$.

10. Nadol'skiy A.L. Rentgenografiya polimerov strukture PA6 i PA66. Ekaterinburg, Ural'skiy federal'nyy universitet, 2013, 45 p.

11. Batyrina R.T. Avtoref. dis. k-ta tekhn. nauk. Kazan', KGTU, 2013, 16 p.

12. Lepeshin S.A. Avtoref. dis. k-ta tekhn. nauk. Kazan', KNITU, 2016, 18 p.

13. Tsvankina A.L. Avtoref. dis. k-ta khim .nauk. M., 1985, 16 p.

14. Karsakova E.V, Kravchenko T.P. Uspekhi $v$ khimii i khimicheskoy tekhnologii, 2008, Vol. 22, No 5 (85). pp. 10-13.

Lazarev Sergey I. - Post Head of the Department, Dr.Sci.Tech., the professor, chair Applied geometry and a computer drawing, TSTU, Tambov, E-mail: geometry@mail.nnn.tstu.ru

Golovin Yuri M. - Associate Professor, Ph.D. in Chemistry, chair Physics, TSTU, Tambov

Yanovsky Hellene Yu. - associate Professor, Geoinformation systems and technologies, Moscow

Lazarev Dmitry S. - student, TSTU, Tambov

Viazovov Sergey A. - Associate Professor, TSTU, chair Applied geometry and a computer drawing, Tambov

Kovaleva Olga A. - Associate Professor, TSTU, chair Applied geometry and a computer drawing, Tambov 